\title{
The role of periostin in neoplastic processes
}

\author{
Katarzyna Ratajczak-Wielgomas ${ }^{1}$, Piotr Dziegiel ${ }^{1,2,3}$ \\ ${ }^{1}$ Department of Histology and Embryology, Wroclaw Medical University, Wroclaw, Poland \\ ${ }^{2}$ Department of Physiotherapy, University School of Physical Education, Wroclaw, Poland \\ ${ }^{3}$ Regional Specialist Hospital, Research and Development Centre, Wroclaw, Poland
}

\begin{abstract}
Periostin, also called osteoblast-specific factor 2 (OSF-2), is a multifunctional glycoprotein that belongs to the group of matricellular proteins. Due to its characteristic molecular structure containing integrin-binding domains, periostin is capable of binding to multiple integrin receptors $(\alpha v \beta 3, \alpha v \beta 5, \alpha 6 \beta 4)$, thus affecting the regulation of the intracellular signaling pathways associated with protein kinases PI3K/AKT and focal adhesion kinase (FAK). This protein thus plays a role in the adhesion process, in the migration of many cells, and importantly, epithelial-mesenchymal transition of cancer cells. Periostin also participates in the processes of angiogenesis and lymphangiogenesis, metastases of cancer cells, and remodeling of the extracellular matrix. Increased expression of periostin has been observed in various tumor types, including breast, NSCLC, colorectal, pancreatic, prostate, and ovarian cancers, as well as tumors of the head and neck, and glioblastomas. Many groups have recently reported on periostin's key role in tumor progression, which suggests that periostin can be considered a potential therapeutic target. (Folia Histochemica et Cytobiologica 2015, Vol. 53, No. 2, 120-132)
\end{abstract}

Key words: periostin; epithelial mesenchymal transition; cancer; metastasis

\begin{abstract}
Abbreviations: $\mathrm{Aa}$ - amino acids, AKT/PKB — serine-threonine protein kinase, BMP-2 - bone morphogenetic protein 2, BIC - bicalutamide, CAFs - cancer-associated fibroblasts, CRC - colorectal cancer, CSCs - cancer stem cell, CTR - C-terminal region, D2-40 - podoplanin, DHT - dihydrotestosterone, ECM - extracellular matrix, ECs - endothelial cells, EGFR - epidermal growth factor receptor, EMT epithelial-mesenchymal transition, EOC - epithelial ovarian cancer tissues, ER — estrogen receptor, F8RA — factor 8 related antigen/von Willebrand factor, FAK — focal adhesion kinase, 5-FU - 5-fluorouracil, FGF-1 - fibroblast growth factor 1, GSCs - glioblastoma
\end{abstract}

Correspondence address: K. Ratajczak-Wielgomas, Ph.D.

Department of Histology and Embryology

Wroclaw Medical University

Chalubinskiego St. 6a, 50-368 Wroclaw

tel.: +48 7178413 65, mobile: +48505860 664,

fax: +48 717840082

e-mail: katarzyna.ratajczak-wielgomas@umed.wroc.pl stem cells, IDC - invasive ductal breast carcinoma, IHC - immunohistochemistry, LCM - laser capture microdissection, LMVD - lymphatic vessel density, LPA - lysophosphatidic acid, MMPs - matrix metalloproteinases, MVD - microvessel density, NSCLC - non-small-cell lung cancer, OSCC — oral squamous-cell carcinoma, OSF-2 - osteoblast-specific factor 2, PDGF - platelet-derived growth factor, PFS - progression-free survival, PI3K - phosphatidylinositol 3-kinase, PIP2 - phosphatidylinositol 4,5-diphosphate, PIP3 - phosphatidylinositol 3,4,5-triphosphate, POSTN - periostin, PR - progesterone receptor, PTEN - phosphatase and tensin homolog, RT-PCR - real-time PCR, SPARC - secreted protein acidic and rich in cysteine, TGF- $\beta$ - transforming growth factor beta, TMA - tissue microarray, TAMs - tumor-associated macrophages,TSP-1, TSP-2 thrombospondin 1 and 2, Twist-basic helix - loop-helix (bHLH) transcription factor, VEGF-A - vascular endothelial growth factor A, VEGF-C - vascular endothelial growth factor C, VEGFR - vascular endothelial growth factor receptor, $\mathrm{WB}$ - western blot, $\alpha$-SMA - alpha smooth muscle actin 


\section{Introduction}

Periostin (POSTN) is a homodimeric glycoprotein with a molecular weight of about $93.3 \mathrm{kDa}$, composed of about 836 aa $[1,2]$. POSTN is a protein produced and secreted by the fibroblasts as a component of the extracellular matrix (ECM) where it is involved in regulating intercellular adhesion [3, 4]. POSTN, originally named Osteoblast-Specific Factor 2 (OSF-2), was first identified in 1993 as a putative cell adhesion protein for preosteoblasts in a mouse osteoblastic MC3T3-E1 cell line [1, 2, 4-6]. Like osteopontin, tenascin-C, thrombospondin 1 and 2 (TSP-1, TSP-2), and cysteine-rich acidic secretory proteins such as SPARC (Secreted Protein Acidic and Rich in Cysteine), it belongs to the group of socalled matricellular proteins [7]. These proteins are secreted into the extracellular matrix, but seem not to play an essential structural role. They rather modulate the basic functions of cells by interacting with their specific receptors, hormone receptors, proteases and other molecules [8].

Human POSTN is encoded by a gene POSTN located on the 13 chromosome (13q13.3), while in mice it is located on chromosome $3[2,7,9]$. Analysis of the sequence shows a high degree of conservation between the species: human and murine POSTN have $89.2 \%$ identity for the entire protein molecule, and $90.1 \%$ identity for the mature form. In turn, the C-terminal region of the protein is less conserved at $85.5 \%[1,2,9]$. The POSTN gene in humans and mice has 23 exons [2,9].

POSTN has a characteristic structure (Figure 1) consisting of four main domains, namely an N-terminus (encoded by exon 1) containing a signal peptide (SP), a cysteine-rich EMI domain (exons 2 and 3) made up of approximately 75 amino acids, and a tandem of four homologous FAS1 domains (exons 3-14). The FAS1 domain is a structural homolog of an insect cell adhesion protein fasciclin I and acts as ligand for cell membrane integrins. The FAS1 domain consists of about 150 amino acids, each containing a single recognition site of the enzyme gamma-carboxylase. The C-terminal region (CTR) of POSTN (exons 15-23) consists of a hydrophilic domain. The $\mathrm{N}$-terminal region regulates cell function by binding to integrins of the cell membrane via its FAS domains. The C-terminal region of the protein regulates the cell-matrix organization and interactions by binding the ECM proteins such as collagen type I and type V, fibronectin, tenascin-C, glycosaminoglycans (e.g. heparin), and POSTN itself $[2,5,10]$.

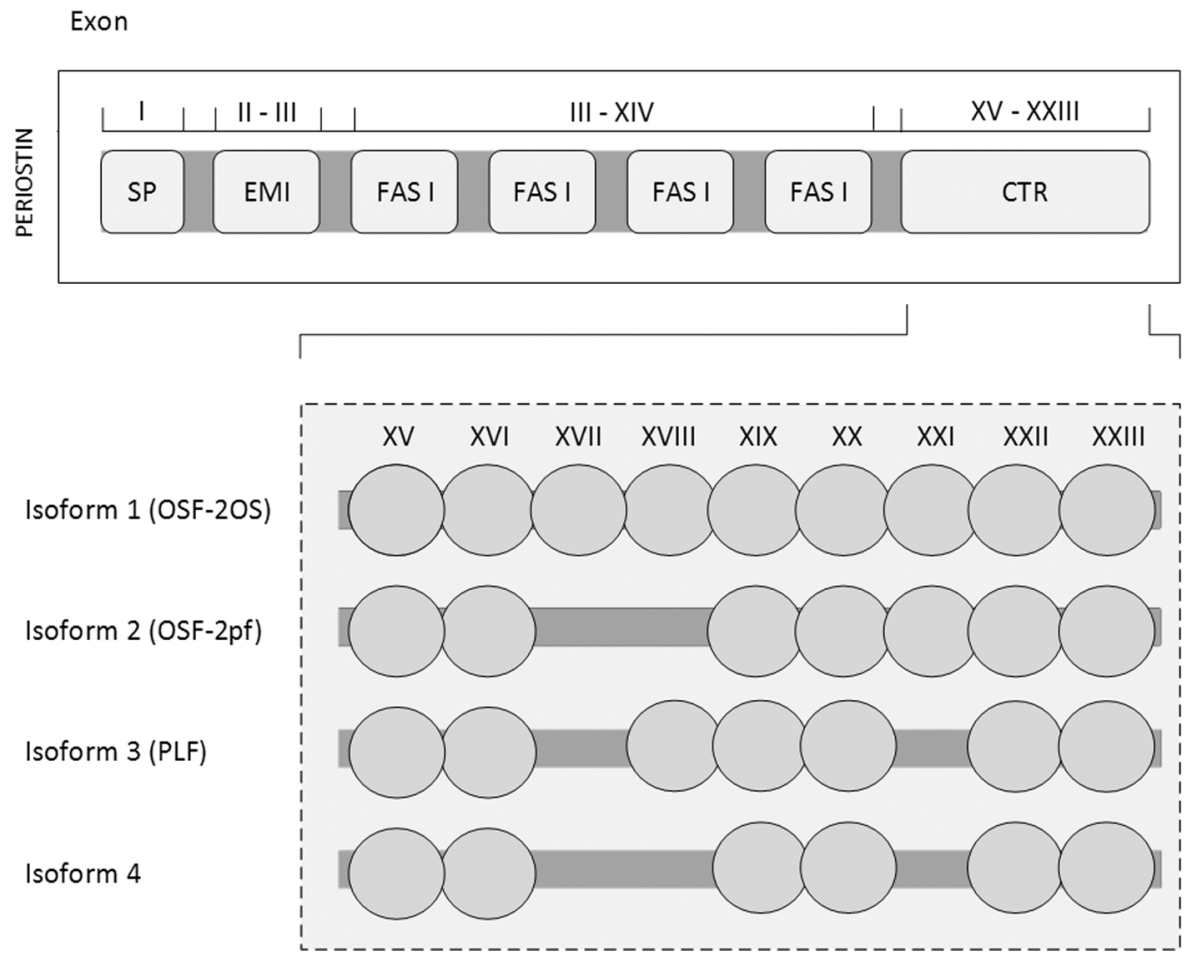

Figure 1. Schematic presentation of the structure of periostin gene and periostin protein isoforms. The periostin gene contains signal peptide (SP), the small cysteine-rich domain (EMI domain), the tandem repeat of 4 FAS1 domains, and the carboxyl-terminal region (CTR). Four periostin isoforms are derived from the alternative splicing of the gene's C-terminal region. Figure composed according to Nuzzo et al. [2], modified 
It is believed that as a result of an alternative mRNA splicing, 8 isoforms of POSTN arise, of which only four have been sequenced: isoform 1 or OSF-2OS (full-length splice variant with all exons), isoform 2 or OSF-2p1 (exon 17 and 18 are absent), isoform 3 or PLF (exon 17 and 21are absent) and isoform 4 (exon 17, 18, and 21 are absent) [2] (Figure 1). POSTN isoforms are composed of 751-836 amino acids, and have molecular masses from 83 to $93 \mathrm{kDa}[2,11]$. The individual isoforms have been identified in various tissues: isoform 1 in human osteosarcomas, isoform 2 in the placenta, isoform 3 in epithelial ovarian carcinoma, and isoforms 2 and 4 in both the normal tissue and cancerous tissue of the urinary bladder $[1,2$, 12-14]. It is therefore believed that the expression of the POSTN isoforms is tissue-specific. The existence of the alternatively spliced forms of POSTN is well known [13, 15], but the functional role of the various isoforms in the process of progression and metastasis of cancer cells is still unclear.

The presence of POSTN has been observed in a variety of normal organs and tissues, including the mammary gland, lung, thyroid, skin, placenta, ovary, as well as periosteum and periodontal ligaments $[5,6$, 10, 16-20]. This glycoprotein plays an important role in the physiological process of epithelial-mesenchymal transition (EMT), which is necessary for the proper development of the embryo [20]. It is also involved in the formation and maintenance of the normal structure of bones and teeth [5] and in the development of the heart (atrioventricular valves) [21]. It has been demonstrated that POSTN plays a significant role in the fibrillogenesis of collagen [22], cell adhesion, and wound healing [7]. Periostin also interacts with the ECM proteins such as fibronectin, tenascin-C, and type $\mathrm{V}$ collagen, taking part in the process of ECM remodeling [9]. POSTN participates in myocardial remodeling after myocardial infarction and also in the pulmonary vascular remodeling process [23-25].

\section{The role of periostin in the development and progression of tumors}

For the last few years, numerous studies have described the role of POSTN in the process of oncogenesis (Figure 2). The exact mechanisms responsible for the effect of POSTN on the progression of cancer and its metastasis are still the subject of an intense research. Numerous studies have confirmed the increased expression of POSTN that accompanies the formation of metastases [9, 10, 26-29]. The formation of metastases requires proteolytic activity of tumor cells, degradation of ECM, migration capacity, and stimulation of angiogenesis.
Periostin was shown to bind to the integrins $\alpha \mathrm{v} \beta 3$, $\alpha \mathrm{v} \beta 5$, and $\alpha 6 \beta 4$, promoting the recruitment of the epidermal growth factor receptor (EGFR) and the activation of the Akt/PKB and FAK-mediated signaling pathways. POSTN-activated signaling pathways promote cell survival, angiogenesis, and resistance to hypoxia-induced cell death $[2,4,9,10]$. POSTN probably exerts its pro-tumorigenic effect not only through its binding to the cell membrane integrins and the consequent activation of intracellular pathways which determine an enhanced invasiveness, but also acting on the ECM fibrillogenesis. Considering that alterations in the ECM components of the tumor microenvironment have a remarkable impact on cancer invasiveness, it is possible that POSTN promotes an ECM re-organization that supports invasion and metastasis (Figure 2) [10].

It is believed that one of the main mechanisms responsible for the invasion and metastasis of cancer cells is also the process of epithelial-mesenchymal transition [30]. EMT is characterized by the loss of the expression of the markers of epithelial cells such as E-cadherin, and by increased expression of mesenchymal cell markers such as vimentin, fibronectin, $\mathrm{N}$-cadherin, alpha smooth muscle actin ( $\alpha$-SMA), as well as increased activity of matrix metalloproteinases (MMPs) like MMP-2, MMP-3 and MMP-9, associated with invasive phenotype [31]. In result, cancer cells acquire the capacity to migrate and invade the surrounding stroma [30]. As has been shown in many studies, EMT may be initiated by signaling pathways activated by tyrosine and serine-threonine kinase activity receptors (e.g., PI3K, EGFR, and c-KIT, which in turn activate the ras-raf-MEK-MAPK pathway) [30]. Numerous reports have indicated that POSTN is one of the main factors affecting the regulation of the intracellular pathway associated with phosphatidylinositol 3-kinase (PI3K) and the serine-threonine protein kinase $\mathrm{AKT} / \mathrm{PKB}$, playing an important role in the regulatory mechanisms involved in EMT, with processes of invasion and metastases (Figure 2) [10, $29,32]$. In the first stage of PI3K/AKT signaling pathway, the tyrosine kinase activity receptor, activated by binding of the ligand, activates PI3K, which converts phosphatidylinositol 4,5-diphosphate (PIP2) to phosphatidylinositol 3,4,5-triphosphate (PIP3). PIP3 contributes to the recruitment of the kinase Akt to the cell membrane, where it is activated due to the phosphorylation of threonine and serine residues. The activated Akt enhances the survival of tumor cells by inhibiting apoptosis while promoting cell proliferation and regulating cell ability to migrate and invade [33-35]. Additionally, it has been shown that PI3K and Akt are involved in the stimulation of EMT 


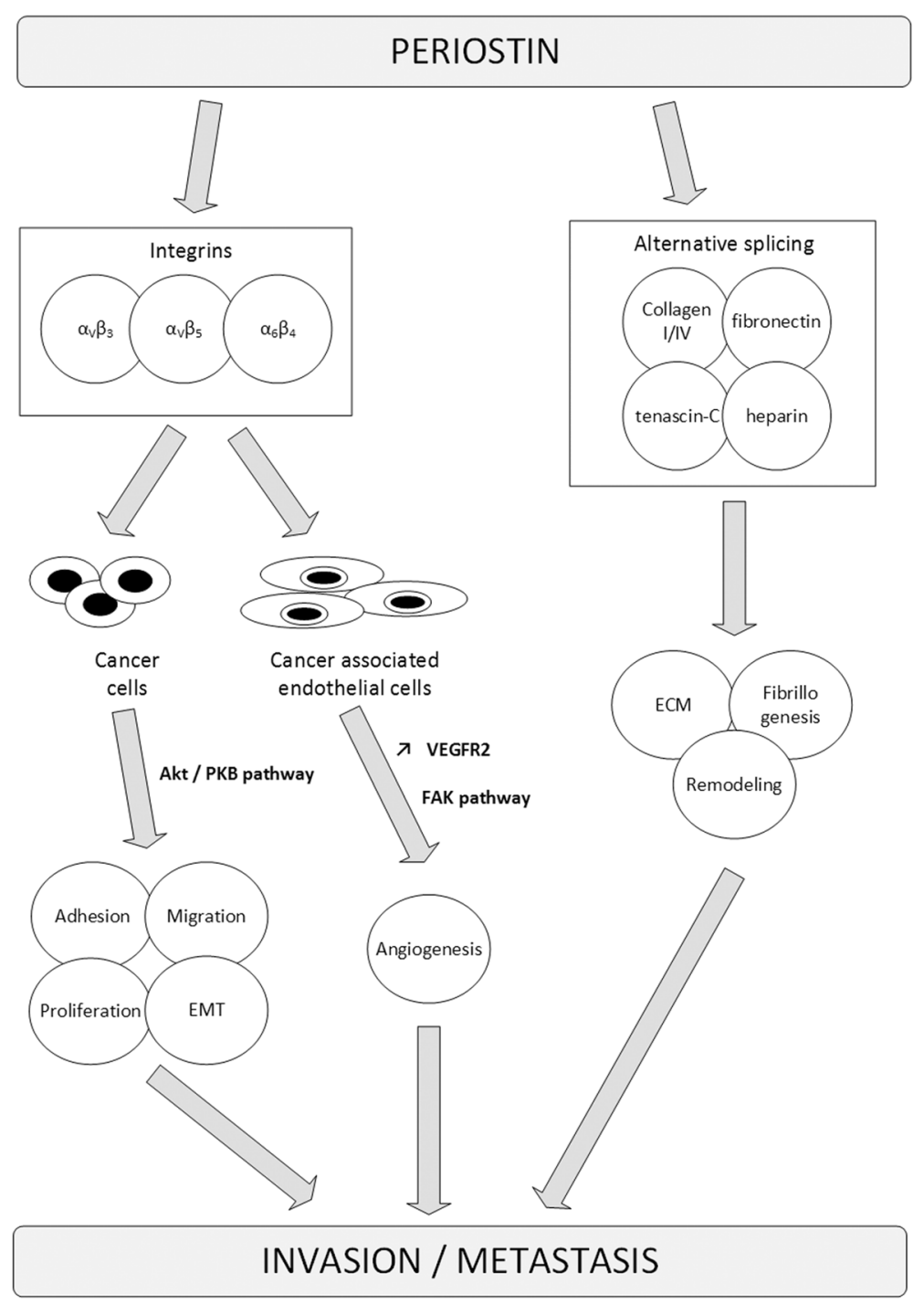

Figure 2. Diagram showing the role of periostin in the process of carcinogenesis. Periostin binds to integrins and activates the Akt/PKB-, and the FAK-mediated signaling pathways, enhancing tumor invasion and metastasis. The isoforms resulting from the alternative splicing of the $\mathrm{C}$-terminal region of periostin gene bind extracellular matrix molecules and affect the general organization of the extracellular matrix. Figure composed according to Morra et al. [10], modified

in the breast cancer cells, either immediately upon activation by TGF- $\beta$ or indirectly, upon activation by the receptors of epidermal growth factor (EGF) or platelet-derived growth factor (PDGF) [36].

POSTN was shown to be not only a marker of EMT, but to be itself an inducer of this phenomenon [37, 38]. Yan et al. [37] have demonstrated that ectopic expression of POSTN in tumorigenic but non-metastatic 293T cells can induce EMT and promote invasion and metastasis in vivo. The upregulation of POSTN expression was accompanied by the upregulation of vimentin, fibronectin, and active MMP-9, while the expression of E-cadherin and $\mathrm{N}$-cadherin was unaltered [37]. POSTN signaling pathway in 293T cells seems to require interaction with $\alpha v \beta 5$ integrin and recruitment of EGFR [37]. In turn, Kim et al. [38] found that upregulation of Akt phosphorylation and Snail by POSTN is involved in the regulation of E-cadherin and the invasiveness of prostate cancer cells. These data suggest that POSTN may play an important role in the progression of cancer.

\section{The role of periostin in angiogenesis and lymphangiogenesis}

Studies in recent years have indicated that POSTN plays a significant role in tumor progression, both in the stimulation of angiogenesis, which involves the formation of new vessels from the endothelial cells of existing vessels, and in the recruitment of endothelial 
progenitor cells from the blood stream, their proliferation, differentiation, and migration to the locations of developing blood vessels [39-41].

POSTN stimulates adhesion and migration of endothelial cells (ECs), among others, through interactions with the integrin $\alpha v \beta 3[4,9,10]$. It has been observed that ECs have particularly high expression of $\alpha \mathrm{v} \beta 3$ when stimulated by growth factors and in inflammation, wound healing, and tumors' blood vessels [42]. Mutual interactions between POSTN and vascular endothelial growth factor (VEGF), which plays a key role in the initiation of physiological and pathological angiogenesis, lymphangiogenesis, and vasculogenesis have been documented [43, 44]. The activation of the VEGF ligand-receptor complex presents one of the best-studied pathways of angiogenesis in cancer. VEGF binds to its receptor (VEGFR) on endothelial cells, stimulating growth, proliferation, and cell migration, which in turn leads to the formation of new blood vessels [43].

In an in vitro model, Shao et al. [44] showed that the angiogenic activity of POSTN correlated with the increased expression of the VEGF receptor (VEGF-R2) by endothelial cells through an integrin $\alpha \mathrm{v} \beta 3$-focal adhesion kinase (FAK)-mediated signaling pathway (Figure 2) [44]. The activation of FAK promotes invasiveness, and $\mathrm{Akt} / \mathrm{PKB}$, a serine/threonine protein kinase, is now recognized as one of the most central regulators of cell survival and proliferation [45]. Akt functions as a key mediator for transducing extracellular and intracellular signals and is positively regulated by PI3-kinase and negatively by phosphatase and tensin homolog (PTEN) [10, 45-47].

In breast cancer, Puglisi et al. [48] reported a significant correlation between the expression of POSTN and VEGF-A and the VEGF-R1 and VEGF-R2 receptors. Similarly, Siriwardena et al. [26] showed that in oral squamous-cell carcinoma (OSCC) blood vessel density of POSTN-positive tumors was higher than those of POSTN-negative tumors. Interestingly, recombinant POSTN enhanced capillary formation in vitro in a concentration-dependent manner [26]. These observations point to the proangiogenic and proliferation-stimulating potential of POSTN. In turn, the in vivo experimental work of Bao et al. [29] revealed that the blood vessel density of the metastatic tumors derived from the POSTN-overexpressing CX-1NS cells was approximately 5-fold higher than in the rare micrometastases of the control cells. These results strongly suggest that POSTN secreted by tumor cells may act in a paracrine manner to induce tumor angiogenesis during metastatic growth [29]. Similarly, in non-small-cell lung cancer (NSCLC), Takanami et al. [49] showed a correlation between the presence of POSTN and the microvessel density, assessed on the basis of the expression of the antigen F8RA (Factor 8 Related Antigen/von Willebrand Factor).

Besides the important role played by POSTN in angiogenesis, it is believed that this protein can also stimulate lymphangiogenesis in tumors. The development of lymphatic vessels and the subsequent involvement of lymph node by cancer cells is one of the main stages of tumor progression [50,51]. Despite significant progress in the assessment of tumor lymphangiogenesis, the mechanism of the formation of new lymphatic vessels in tumor tissue is still relatively unknown, compared to the more accurately described tumor angiogenesis. Kudo et al. [52] showed a significant correlation between the expression of POSTN and the factor regulating the growth of lymphatic vessels, VEGF-C. In addition, in an in vitro model they showed that, independently of VEGF-C, POSTN can induce the growth of lymphatic endothelial cells by activating the tyrosine kinases Src and the protein kinase Akt. It was reported that lymphangiogenesis could be promoted by POSTN itself and by the POSTN-induced upregulation of VEGF-C [52]. Similarly, Takanami et al. [49] demonstrated in non-small-cell lung cancer a significant relationship between the presence of POSTN and the lymphatic vessel density (LMVD); the lymph vessels were labeled with podoplanin (D2-40), a glycoprotein produced by the vascular endothelium of lymph vessels. POSTN may be an important factor in the initiation and stimulation of both the angiogenesis and lymphangiogenesis in tumors, but further studies are needed to thoroughly elucidate these mechanisms.

\section{Regulation of periostin expression in the process of carcinogenesis}

Several studies have shown that the expression of POSTN can be regulated in vitro by specific growth factors, including TGF $-\beta 1$ and bone morphogenetic protein 2 (BMP-2) $[5,53]$. In view of the fact that TGF- $\beta$ is one of the factors that promote EMT and the formation of distant metastases, it is believed that POSTN may act as mediator of the pro-metastatic activity of TGF- $\beta 1$ in certain cancer types [9]. It has also been demonstrated that the expression of POSTN can be regulated by the basic helix-loop-helix (bHLH) transcription factor Twist, which is an inducer of the EMT process [54]. Oshima et al. found that Twist was associated with the POSTN promoter sequence in undifferentiated preosteoblasts and stimulated POSTN expression [54]. Moreover, the increased expression of fibroblast growth factor 1 (FGF-1) and angiotensin 2 in response to anaerobic conditions in pulmonary arterial smooth muscle cells led to the increased expression of POSTN through the activation 
of the PI3-K/Akt/p70S6K, Ras/MEK1/2/ERK1/2, and Ras/p38MAPK signaling pathways [16]. The expression of POSTN was found to be regulated by Wnt-3 in mouse mammary epithelial cells [55] and interleukins, such as IL-4 and IL-13 in lung fibroblasts [18].

Most of the data on the mechanisms that regulate the expression of POSTN in different cell types are derived from the studies of embryonic development. Further experiments to identify the mechanisms which control POSTN expression in the process of tumorigenesis are thus required.

\section{Periostin expression in different types of tumors}

Increased expression of POSTN has been observed in various tumor types, including breast [44, 48, 56-58], NSCLC [27, 49, 59-62], colorectal [19, 29, 63], stomach cancers [64-68], pancreatic [32, 69], prostate [70-75], ovarian cancer [76-79], and glioblastomas [80-82] (Table 1).

\section{Periostin expression in breast cancer}

One of the best studied cancers in terms of POSTN expression is breast cancer. Expression of POSTN was mainly localized in the tumor stroma and in the cytoplasm of the breast cancer cells (Figure 3 ).

Puglisi et al. [48] reported significantly increased expression of POSTN in breast cancer, as compared to the normal breast tissues. Using immunohistochemistry (IHC), POSTN presence was mainly observed in the cytoplasm of the tumor cells $(57 \%)$. However, in $12 \%$ of cases, nuclear expression of POSTN was noted. A significantly positive correlation has been shown between nuclear expression of POSTN and tumor size, progesterone (PR) and expression of estrogen receptors (ER), VEGF-A, VEGF-R1 and VEGF-R2, suggesting that the nuclear localization of this protein may induce relevant biological effects [48]. A significant correlation was found between the cytoplasmic localization of POSTN and the size of the tumor and the expression of VEGF-A, progesterone and VEGFR-1 receptors. However, the cytoplasmic expression of POSTN did not correlate with the stage of the tumor, nodal status, ER or HER-2 receptor status, or the expression of the proliferative antigen Ki-67 [48]. The expression of POSTN was also analyzed in the soluble fraction of nuclear and cytoplasmic proteins in MCF-7 and MDA-468 cell lines of breast cancer using IHC and Western blot (WB) methods [48]. In both cell lines, POSTN was localized either in nuclear and cytoplasmic fractions. In addition, in MCF-7 cells the nuclear localization of POSTN was also shown by transfection of a vector expressing a GFP-POSTN chimeric protein. Furthermore, real-time PCR (qRT-PCR) showed a 50-fold lower expression of POSTN mRNA in the MCF-7 cell line of breast cancer in relation to MDA-468 cell, which was consistent with the results of IHC [48]. A significant role of POSTN in breast cancer angiogenesis has been demonstrated, showing a positive correlation between the presence of POSTN and the expression of proangiogenic factor VEGF-A and its receptors VEGF-R1 and VEGF-R2 [48]. Similar observations concerning the participation of POSTN in the process of angiogenesis were reported by Shao et al. [44], who used cell lines overexpressing POSTN, such as 293T cell line derived from human kidney epithelial cells, B16F1 the highly invasive mouse melanoma cell line and MDA-MB-231 the metastatic human breast cancer line. Tumor cell lines engineered to overexpress POSTN showed a phenotype of an accelerated growth and angiogenesis as xenografts in immunocompromised animals [44]. In vitro studies showed that POSTN promoted angiogenesis via the up-regulation of VEGF-R2 expression in endothelial cells through an integrin $\alpha \mathrm{v} \beta 3$-FAK-mediated signaling pathway [44]. Moreover, by the use of the gene arrays analysis, an average 20-fold higher expression of POSTN mRNA in samples of breast cancer as compared to the normal breast tissue was observed [44]. These results were also confirmed by the WB and IHC methods, which showed strong expression of the investigated proteins predominantly in the cytoplasm of tumor cells [44]. In later studies, Zhang et al. [56] showed increased POSTN levels and significantly increased POSTN mRNA expression in cancerous tissue compared to normal breast tissue. In contrast to the results of Puglisi et al. [48], the authors observed POSTN localization predominantly in the space surrounding the tumor cells and in a few cases in the membrane and cytoplasm of tumor cells [56]. They also demonstrated the strong expression of POSTN in tumor cell metastases to lymph nodes and a positive correlation between the expression of POSTN and the stage of breast cancer, which indicates the significant role of POSTN in the progression of this type of cancer [56].

In more recent study, Xu et al. [57] assessed the expression of POSTN in breast cancer stem cells (CSCs), identified by the presence of specific markers such as $\mathrm{CD} 44^{+}$and $\mathrm{CD} 24^{-}\left(\mathrm{CD} 44^{+} / \mathrm{CD} 24^{-}\right.$cells). They showed that CSC cells were more likely to generate new tumors in mice and cell microspheres that were deficient in NOD/SCID compared to the control group.

The authors showed significantly increased expression of POSTN in CSCs compared to the CD44- tumor 
Table 1. Expression of periostin in gastric, pancreatic, prostate and ovarian cancers, and in glioblastomas

\begin{tabular}{|c|c|c|c|}
\hline Cancer type & Evaluation method & Periostin expression/function & Reference \\
\hline \multirow{4}{*}{$\begin{array}{l}\text { Gastric } \\
\text { cancer }\end{array}$} & Microarray data sets & $\begin{array}{l}\text { Higher POSTN mRNA expression in cancer tissues from stage II, III } \\
\text { and IV gastric cancer compared to normal tissues. Correlation between } \\
\text { POSTN expression and tumor progression }\end{array}$ & \multirow{4}{*}{ [64] } \\
\hline & In situ hybridization & $\begin{array}{l}\text { POSTN mRNA expression in cancer-associated fibroblasts (CAFs), but } \\
\text { not in tumor cells themselves }\end{array}$ & \\
\hline & In vitro & $\begin{array}{l}\text { POSTN enhanced the growth of OCUM-2MLN and OCUM-12 diffuse } \\
\text {-type gastric cancer cell lines }\end{array}$ & \\
\hline & IHC & $\begin{array}{l}\text { Stromal POSTN expression increased with stage progression in both } \\
\text { intestinal-type and diffuse-type gastric cancer. CAFs are the primary so- } \\
\text { urce of POSTN, which facilitates tumor cell invasion by inducing EMT }\end{array}$ & \\
\hline \multirow{2}{*}{$\begin{array}{l}\text { Gastric } \\
\text { cancer }\end{array}$} & IHC & $\begin{array}{l}\text { Periglandular POSTN expression was lower in primary gastric cancers } \\
\text { compared to normal gastric mucosa. Its expression was downregulated } \\
\text { in metastatic lymph nodes compared with matched primary tumor } \\
\text { tissues, and was negatively associated with tumor stage }\end{array}$ & \multirow{2}{*}{ [65] } \\
\hline & $\begin{array}{l}\text { In vitro } \\
\mathrm{RT}-\mathrm{PCR}\end{array}$ & $\begin{array}{l}\text { Epithelial cell-derived POSTN functions as a tumor-suppressor through } \\
\text { stabilizing p53 and E-cadherin proteins via the Rb/E2F1/p14ARF/Mdm2 } \\
\text { signaling pathway }\end{array}$ & \\
\hline $\begin{array}{l}\text { Gastric } \\
\text { cancer }\end{array}$ & In vitro & $\begin{array}{l}\text { POSTN confers protection against cisplatin or 5-FU in SGC-7901 } \\
\text { gastric cancer cells, through activating of the Akt pathway and inhibiting } \\
\text { the p53 expression. POSTN may be a potential therapeutic target in } \\
\text { gastric cancer }\end{array}$ & [66] \\
\hline \multirow[b]{2}{*}{$\begin{array}{l}\text { Gastric } \\
\text { cancer }\end{array}$} & RT-PCR & Increased POSTN mRNA expression in gastric cancer tissues & \multirow[b]{2}{*}{ [67] } \\
\hline & IHC & $\begin{array}{l}\text { Higher POSTN expression in gastric cancer tissues and metastatic } \\
\text { lymph nodes compared to normal gastric tissues and benign gastric } \\
\text { diseases. Correlation with the TNM stage of gastric cancer }\end{array}$ & \\
\hline $\begin{array}{l}\text { Gastric } \\
\text { cancer }\end{array}$ & In vitro & $\begin{array}{l}\text { POSTN elevates cell proliferation, invasion, and epithelial-mesenchy- } \\
\text { mal transition in nicotine-induced gastric cancer }\end{array}$ & [68] \\
\hline \multirow{4}{*}{$\begin{array}{l}\text { Pancreatic } \\
\text { cancer }\end{array}$} & In situ hybridization & Presence of POSTN mRNA exclusively in the cytoplasm of tumor & \multirow{4}{*}{ [32] } \\
\hline & IHC & Expression of POSTN only in the tumor stroma but not within cancer & \\
\hline & ELISA & $\begin{array}{l}\text { Higher levels of serum POSTN in pancreatic cancer patients, as compa- } \\
\text { red to a healthy group }\end{array}$ & \\
\hline & In vitro & $\begin{array}{l}\text { Promotes invasiveness by stimulating motility and enhances the survival } \\
\text { of tumor cells exposed to hypoxic conditions }\end{array}$ & \\
\hline \multirow{2}{*}{$\begin{array}{l}\text { Pancreatic } \\
\text { cancer }\end{array}$} & IHC & $\begin{array}{l}\text { Correlation between neoplastic stromal expression of POSTN and } \\
\text { depth of invasion and lymph node metastasis. Stromal or epithelium } \\
\text { expression of POSTN was associated with poor survival }\end{array}$ & \multirow{2}{*}{ [69] } \\
\hline & In vitro & $\begin{array}{l}\text { Promotes proliferation and invasiveness of pancreatic cancer cells. } \\
\text { POSTN may be involved in the progression and invasion of pancreatic } \\
\text { cancer }\end{array}$ & \\
\hline $\begin{array}{l}\text { Prostate } \\
\text { cancer }\end{array}$ & IHC & $\begin{array}{l}\text { Over-expressed in stromal and epithelial compartment. Stromal expres- } \\
\text { sion correlated with the degree of malignancy. Correlation between } \\
\text { epithelial expression and degree of malignancy, pT status }\end{array}$ & [70] \\
\hline \multirow{2}{*}{$\begin{array}{l}\text { Prostate } \\
\text { cancer }\end{array}$} & \multirow[t]{2}{*}{ IHC } & $\begin{array}{l}\text { High stromal expression was associated with shorter survival. A low } \\
\text { epithelial score correlated with shorter PSA-free survival }\end{array}$ & \multirow[t]{2}{*}{ [71] } \\
\hline & & POSTN might represent a novel prognostic marker for prostate cancer & \\
\hline Prostate cancer & IHC & Stromal expression correlated with the degree of malignancy & [72] \\
\hline Prostate cancer & $\begin{array}{l}\text { Liquid chromatography- } \\
\text {-tandem mass spectrometry, } \\
\text { ELISA }\end{array}$ & $\begin{array}{l}\text { Higher expression of POSTN in aggressive prostate tumor compared to } \\
\text { both non-aggressive tumor and normal prostate tissue. POSTN expres- } \\
\text { sion may be associated with aggressive prostate cancer }\end{array}$ & [73] \\
\hline Prostate cancer & In vivo & $\begin{array}{l}\text { Silencing expression by RNA interference inhibited proliferation and } \\
\text { migration of LNCaP cell in vivo }\end{array}$ & [74] \\
\hline Prostate cancer & In vitro & $\begin{array}{l}\text { POSTN transfection stimulated LNCaP cell growth. POSTN transfec- } \\
\text { tion did not interfere with the stimulatory effect of dihydrotestosterone } \\
\text { (DHT); bicalutamide (BIC) had an inhibitory effect on cell proliferation }\end{array}$ & [75] \\
\hline
\end{tabular}


Table 1 (cont.). Expression of periostin in gastric, pancreatic, prostate and ovarian cancers, and in glioblastomas

\begin{tabular}{|c|c|c|c|}
\hline \multirow{3}{*}{ Ovarian cancer } & cDNA microarray & $\begin{array}{l}\text { Correlation between expression of POSTN and higher tumor stage and } \\
\text { cancer recurrence }\end{array}$ & \multirow{3}{*}{ [76] } \\
\hline & $\begin{array}{l}\text { IHC } \\
\text { Northern blot }\end{array}$ & $\begin{array}{l}\text { Higher expression of POSTN mRNA and protein levels in ovarian } \\
\text { tumors compared to normal/benign tumor samples }\end{array}$ & \\
\hline & $\begin{array}{l}\text { In vitro } \\
\text { In vivo }\end{array}$ & $\begin{array}{l}\text { Overexpression of POSTN in OVCAR-3 and OV2008 cell lines has no } \\
\text { effect on the proliferation. Promotes intraperitoneal tumor metastatic } \\
\text { growth in immunodeficient mice. Induces tumor angiogenesis and inhi- } \\
\text { bits tumor cell apoptosis }\end{array}$ & \\
\hline Ovarian cancer & In vivo & $\begin{array}{l}\text { Antibody directed against POSTN (MZ-1) inhibits the development of } \\
\text { primary tumors derived from the periostin-expressing ovarian cancer } \\
\text { cell line A2780 }\end{array}$ & [77] \\
\hline \multirow[t]{2}{*}{ Ovarian cancer } & IHC & $\begin{array}{l}\text { Expression of POSTN in cancer-associated stromal fibroblasts, but not } \\
\text { in cancer cells. The } 5 \text {-year survival rate was better in patients with nega- } \\
\text { tive POSTN expression than in those with positive POSTN expression. } \\
\text { POSTN expression in cancer stroma may have prognostic relevance in } \\
\text { ovarian cancer }\end{array}$ & \multirow[t]{2}{*}[78]{} \\
\hline & In vitro & $\begin{array}{l}\text { Lysophosphatidic acid (LPA)-induced expression of POSTN in cancer } \\
\text {-associated stromal cells }\end{array}$ & \\
\hline Ovarian cancer & microarrays & $\begin{array}{l}\text { Overall survival was significantly shorter for patients with tumors } \\
\text { expressing genes associated with POSTN/TGFBI compared to patients } \\
\text { with tumors expressing genes associated with ESR1/WT1 }\end{array}$ & [79] \\
\hline Glioblastoma & $\begin{array}{l}\text { Immunofluorescence } \\
\text { IHC }\end{array}$ & $\begin{array}{l}\text { Glioblastoma stem cells (GSCs) recruit and activate tumor-associated } \\
\text { macrophages (TAMs) by secreting POSTN }\end{array}$ & [80] \\
\hline Glioblastoma & $\begin{array}{l}\text { RT-PCR } \\
\text { IHC }\end{array}$ & $\begin{array}{l}\text { POSTN expression levels correlated with tumor grade and recurrence, } \\
\text { and inversely with survival, in all grades of human glioma. POSTN } \\
\text { upregulation may contribute to invasion and stem cell phenotypes }\end{array}$ & [81] \\
\hline Glioblastoma & IHC & $\begin{array}{l}\text { Expression of POSTN in the cytoplasm and membrane of glioma cells. } \\
\text { The cases with highly expressed POSTN protein attained a significantly } \\
\text { poor postoperative disease-specific survival. POSTN was detected as the } \\
\text { independent prognostic factor }\end{array}$ & [82] \\
\hline
\end{tabular}
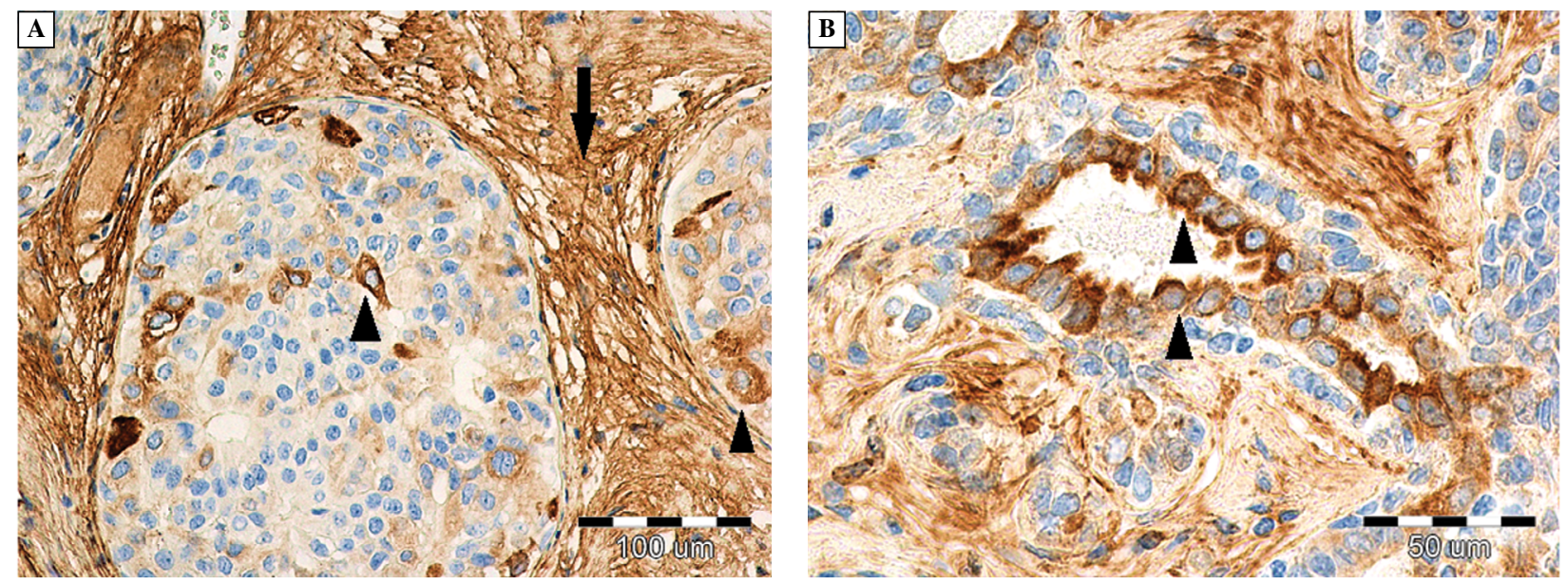

Figure 3. Expression of periostin in invasive ductal breast carcinoma. Periostin was located in the tumor stroma (arrows) (A) and in the cytoplasm (arrowheads) of the breast cancer cells (A, B). Original magnifications: A $-\times 200 ; B-\times 400$. For the immunohistochemical demonstration of periostin Autostainer Link 48 (Dako, Glostrup, Denmark) with the visualization system of EnVisione FLEX, High pH (Dako) was used. Periostin was detected by the incubation of deparaffinized sections with primary anti-periostin antibody (rabbit polyclonal antibody, Novus Biologicals, Littleton, CO, USA) 
cells, CD $44^{+} / \mathrm{CD} 24^{+}$tumor cells, and unsorted cells [57]. The immunohistochemical staining revealed that the expression of POSTN mainly occurred in the cytoplasm and plasma membrane of the breast cancer cells. In the prognostic analysis, patients with cancer expressing POSTN, along with age, histological grade, lymph node metastasis, and triple-negative breast cancer, were shown to attain a poorer disease-specific survival than those with no or low expressed POSTN. In addition, multivariate analysis demonstrated that high POSTN expression may be an independent prognostic factor in breast cancer [57].

\section{Periostin expression in non-small-cell lung cancer (NSCLC)}

As with other cancers of epithelial origin, non-small-cell lung cancer (NSCLC) was examined for POSTN expression [27, 49, 59, 61, 62].

Using the technique of in situ RNA hybridization, Sasaki et al. [27] observed a strong expression of POSTN at the tumor periphery of lung carcinoma tissue. However, no presence of POSTN was found within the tumor tissue. In addition, no significant differences were found in the concentration of POSTN in the blood serum of NSCLC patients or healthy controls. Furthermore, no significant correlation was found between the serum concentrations of POSTN and gender, $\mathrm{N}$ status (lymph node metastasis), $\mathrm{T}$ (tumor size) and bone metastasis. However, the subgroup of the NSCLC patients with high POSTN serum level had significantly poorer survival than the patients with normal POSTN concentration [27]. These observations indicate that a high concentration of POSTN in the serum may be a negative prognostic factor for NSCLC. Takanami et al. [49] found significant correlation between POSTN expression determined by immunohistochemistry and tumor size, lymph node metastasis, disease stage, and lymphatic invasion. A significant positive correlation was also found between POSTN expression and microvessel density and density of lymphatic microvessels (LMVD). Moreover, the five-year survival rates were better in patients with negative tumor POSTN expression than in those with positive POSTN expression [49]. It thus seems that the presence of POSTN expression is associated with an increased risk of tumor progression, and worse prognosis for NSCLC patients. In contrast, other authors showed presence of POSTN in either stroma or tumor epithelia [59]. There was a significant correlation seen between POSTN expression and male gender, higher stage, higher pT category, and larger tumor size. The expression of POSTN in the stroma of the tumor also correlated positively with tumor relapse. The univariate analysis confirmed that high expression of POSTN in the tumor stroma correlated with decreased progression-free survival (PFS) [59]. Similarly, Morra et al. [60] showed increased expression of POSTN both on the mRNA and protein levels in NSCLC tissue, as compared to normal lung tissue with significantly higher levels in the adenocarcinoma compared to the squamous cell subtype. The localization of POSTN was observed mainly in the cytoplasm of tumor epithelia, in stromal cells, and in the extracellular matrix. A significant correlation was found between the expression of POSTN in tumor cells, and with higher tumor grade and larger tumor size. Using the technique of laser capture microdissection (LCM), the authors established that both tumor epithelia and stromal cells can be a source of POSTN production in NSCLC [60]. It was shown that POSTN may promote proliferation and migration of A549 lung cancer cells by inducing the expression of vimentin and $\mathrm{N}$-cadherin, key mesenchymal cell markers of epithelial-mesenchymal transition (EMT), and downregulating E-cadherin expression [61]. In addition, POSTN concentration was evaluated in the serum of and compared to that of a healthy group. Consistent with the results obtained by Sasaki et al. [27], in NSCLC patients no significant correlations between the serum concentration of POSTN and patients' gender, age, pathological type, TNM stage, lymph node status, tumor size $(\mathrm{G})$ and invasiveness were found [61]. However, in a more recent report, the same group showed significantly increased expression of POSTN on the protein, but not at the mRNA, level in NSCLC patients compared to the normal lung tissue with high POSTN immunoreactivity in the mesenchymal areas, but not in the cancer cells [62]. The use of multivariate analysis demonstrated that the high expression of POSTN may be an independent prognostic factor in NSCLC playing an important role in the progression of NSCLC [62].

\section{Periostin expression in colorectal cancer (CRC)}

Periostin expression has also been studied in colorectal cancer (CRC). Bao et al. [29], using the Northern blot technique, demonstrated the increased expression of POSTN in over $80 \%$ of human primary colon cancer samples. It was found that the high level of POSTN significantly correlated with the presence of liver metastases. The results were also confirmed by IHC. The presence of POSTN was observed mainly in areas containing cancer cells of the primary colon tumors and metastatic tumors in the liver. In contrast, POSTN was undetectable in normal colon mucosa. Furthermore, POSTN expression was at a statistically 
higher level in the hepatic metastases relative to the colon primary tumors [29]. These observations indicate that high level of POSTN expression may be closely associated with metastasized colon tumors. The authors also showed that POSTN interacts with the $\alpha \mathrm{v} \beta 3$ integrin and induces a signaling pathway involving $\mathrm{AKT} / \mathrm{PKB}$ protein kinase, thereby facilitating of metastatic growth of colon cancer [29]. Likewise, Tai et al. [19] found that POSTN was upregulated in colorectal cancer (CRC) and its liver metastasis. Also in vitro studies suggest that POSTN promotes growth and cell proliferation in CRC. It was also shown that exposing MIP101 colorectal cancer cells to anti-POSTN antibodies activates apoptotic mechanisms and increases the effectiveness of chemotherapy [19]. The authors of the studies point to the potential role of POSTN as a therapeutic target for patients with CRC [19]. Given the important role of POSTN in the formation of metastases, it was proposed [19, 29] that this glycoprotein may be a potential therapeutic target in metastatic colorectal cancer.

On the other hand, Xiao et al. [63] evaluated the effect of POSTN on the chemoresistance of colorectal cancer cell lines (SW480 and HT-29) treated with oxaliplatin and 5-fluorouracil (5-FU) [63]. It was found that silencing mRNA expression of POSTN using siRNA suppressed the expression of survivin, a protein that inhibits apoptosis in CRC cell lines. POSTN induced the chemoresistance of CRC cells by activating the PI3K/AKT/surviving signaling pathways [63].

The presence of POSTN has been also studied in other types of tumors as summarized in Table 1.

\section{Conclusions}

POSTN, as a multifunctional protein, plays an important role in tumor development and is upregulated in a wide variety of malignant neoplasms such as breast, colon, lung, pancreatic, ovarian, gastric, head and neck, thyroid and prostate cancer, as well as in glioblastomas. In most tumors POSTN expression is observed mainly in the tumor stroma and in the cytoplasm of cancer cells; however, not in all cases. POSTN binding to cell membrane integrins activates the Akt/PKB- and FAK-mediated signaling pathways which lead to increased cell survival, angiogenesis, invasion and metastasis. It has been suggested that high POSTN expression may be an independent prognostic factor in breast cancer and in non-small-cell lung cancer. POSTN expression is associated with an increased risk of progression and invasion of pancreatic cancer. Many data suggest that POSTN may be considered as a marker of the progression of prostate as well as ovarian cancer, and glioblastomas. Numerous studies have indicated that POSTN expression may serve as a valuable prognostic tool in oncology. It is hoped that the evaluation of POSTN levels in blood or its tissue expression by immunohistochemistry or real-time PCR may be helpful in rapid identification of highly invasive tumors and create an opportunity to develop new targeted therapies.

\section{Acknowledgements}

This publication was supported by scientific grants from the Wrovasc Integrated Cardiovascular Centre project, co-financed by the European Regional Development Fund, within the Innovative Economy Operational Program, 2007-2013.

\section{References}

1. Takeshita S, Kikuno R, Tezuka K, Amann E. Osteoblast-specific factor 2: cloning of a putative bone adhesion protein with homology with the insect protein fasciclin I. Biochem J. 1993;294:271-278. PMID: 8363580.

2. Nuzzo PV, Buzzatti G, Ricci F et al. Periostin: a novel prognostic and therapeutic target for genitourinary cancer? Clin Genitourin Cancer. 2014;12:301-311. doi: 10.1016/j. clgc.2014.02.005.

3. Sehra S, Yao W, Nguyen ET et al. Periostin regulates goblet cell metaplasia in a model of allergic airway inflammation. J Immunol. 2011;186:4959-4966. doi: 10.4049/jimmunol.1002359.

4. Kudo Y, Siriwardena BS, Hatano H, Ogawa I, Takata T. Periostin: novel diagnostic and therapeutic target for cancer. Histol Histopathol. 2007;22:1167-1174. PMID:17616943.

5. Horiuchi K, Amizuka N, Takeshita S et al. Identification and characterization of a novel protein, periostin, with restricted expression to periosteum and periodontal ligament and increased expression by transforming growth factor beta.J Bone Miner Res. 1999;14:1239-1249. doi: 10.1359/jbmr.1999.14.7.1239.

6. Litvin J, Selim AH, Montgomery MO et al. Expression and function of periostin-isoforms in bone. J Cell Biochem. 2004;92:1044-1061. doi: 10.1002/jcb.20115.

7. Hamilton DW. Functional role of periostin in development and wound repair: implications for connective tissue disease. J Cell Commun Signal. 2008;2:9-17. doi: 10.1007/s12079-008-0023-5.

8. Bornstein P. Matricellular proteins: an overview. J Cell Commun Signal. 2009;3:163-165. doi: 10.1007/s12079-009-0069-z.

9. Ruan K, Bao S, Ouyang G. The multifaceted role of periostin in tumorigenesis. Cell Mol Life Sci. 2009;66:2219-2230. doi: 10.1007/s00018-009-0013-7.

10. Morra L, Moch H. Periostin expression and epithelial-mesenchymal transition in cancer: a review and an update. Virchows Arch. 2011;459:465-475. doi: 10.1007/s00428-011-1151-5.

11. Kyutoku M, Taniyama $\mathrm{Y}$, Katsuragi $\mathrm{N}$ et al. Role of periostin in cancer progression and metastasis: inhibition of breast cancer progression and metastasis by anti-periostin antibody in a murine model. Int J Mol Med. 2011;28:181-186. doi: 10.3892/ijmm.2011.712.

12. Gillan L, Matei D, Fishman DA, Gerbin CS, Karlan BY, Chang DD. Periostin secreted by epithelial ovarian carcinoma is a ligand for alpha(V)beta(3) and alpha(V)beta(5) integrins and promotes cell motility. Cancer Res. 2002;62:5358-5364. PMID: 12235007. 
13. Kim CJ, Isono $\mathrm{T}$, Tambe $\mathrm{Y}$ et al. Role of alternative splicing of periostin in human bladder carcinogenesis. Int J Oncol. 2008;32:161-169. doi: 10.3892/ijo.32.1.161.

14. Litvin J, Zhu S, Norris R, Markwald R. Periostin family of proteins: therapeutic targets for heart disease. Anat Rec A Discov Mol Cell Evol Biol. 2005;287:1205-1212. doi: 10.1002/ar.a. 20237.

15. Kim CJ, Yoshioka N, Tambe Y, Kushima R, Okada Y, Inoue H. Periostin is down-regulated in high grade human bladder cancers and suppresses in vitro cell invasiveness and in vivo metastasis of cancer cells. Int J Cancer. 2005;117:51-58. doi: 10.1002/ijc.21120.

16. Li P, Oparil S, Feng W, Chen YF. Hypoxia-responsive growth factors upregulate periostin and osteopontin expression via distinct signaling pathways in rat pulmonary arterial smooth muscle cells. J Appl Physiol. 2004;97:1550-1558. doi: 10.1152/ japplphysiol.01311.2003.

17. Ouyang G, Liu M, Ruan K, Song G, Mao Y, Bao S. Upregulated expression of periostin by hypoxia in non-small-cell lung cancer cells promotes cell survival via the Akt/PKB pathway. Cancer Lett. 2009;281:213-219. doi: 10.1016/j. canlet.2009.02.030.

18. Takayama G, Arima K, Kanaji T et al. Periostin: a novel component of subepithelial fibrosis of bronchial asthma downstream of IL-4 and IL-13 signals. J Allergy Clin Immunol. 2006;118:98-104. doi: 10.1016/j.jaci.2006.02.046.

19. Tai IT, Dai M, Chen LB. Periostin induction in tumor cell line explants and inhibition of in vitro cell growth by anti-periostin antibodies. Carcinogenesis. 2005;26:908-915. doi: 10.1093/ carcin/bgi034.

20. Lindsley A, Snider P, Zhou H et al. Identification and characterization of a novel Schwann and outflow tract endocardial cushion lineage-restricted periostin enhancer. Dev Biol. 2007;307:340-355. doi: 10.1016/j.ydbio.2007.04.041.

21. Conway SJ, Molkentin JD. Periostin as a heterofunctional regulator of cardiac development and disease. Curr Genomics. 2008;9:548-555. doi: 10.2174/138920208786847917.

22. Norris RA, Damon B, Mironov V et al. Periostin regulates collagen fibrillogenesis and the biomechanical properties of connective tissues. J Cell Biochem. 2007;101:695-711. doi: $10.1002 /$ jcb. 21224.

23. Kuhn B, del Monte F, Hajjar RJ et al. Periostin induces proliferation of differentiated cardiomyocytes and promotes cardiac repair. Nat Med. 2007;13:962-969. doi: 10.1038/nm1619.

24. Shimazaki M, Nakamura K, Kii I et al. Periostin is essential for cardiac healing after acute myocardial infarction. J Exp Med. 2008;205:295-303. doi: 10.1084/jem.20071297.

25. Chen YF, Feng JA, Li P, Xing D, Ambalavanan N, Oparil S. Atrial natriuretic peptide-dependent modulation of hypoxia-induced pulmonary vascular remodeling. Life Sci. 2006;79:1357-1365. doi: 10.1016/j.lfs.2006.03.051.

26. Siriwardena BS, Kudo Y, Ogawa I et al. Periostin is frequently overexpressed and enhances invasion and angiogenesis in oral cancer. Br J Cancer. 2006;95:1396-1403. doi: 10.1038/ sj.bjc. 6603431.

27. Sasaki H, Dai M, Auclair D et al. Serum level of the periostin, a homologue of an insect cell adhesion molecule, as a prognostic marker in non-small cell lung carcinomas. Cancer. 2001;92:843-848. PMID: 11550156.

28. Sasaki H, Sato Y, Kondo S et al. Expression of the periostin mRNA level in neuroblastoma.J Pediatr Surg. 2002;37:1293-1297. doi: 10.1053/jpsu.2002.34985.

29. Bao S, Ouyang G, Bai X et al. Periostin potently promotes metastatic growth of colon cancer by augmenting cell survi- val via the Akt/PKB pathway. Cancer Cell. 2004;5:329-339. PMID: 15093540.

30. Guarino M. Epithelial-mesenchymal transition and tumour invasion. Int J Biochem Cell Biol. 2007;39:2153-2160. doi: 10.1016/j.biocel.2007.07.011.

31. Sarrio D, Rodriguez-Pinilla SM, Hardisson D, Cano A, Moreno-Bueno G, Palacios J. Epithelial-mesenchymal transition in breast cancer relates to the basal-like phenotype. Cancer Res. 2008;68:989-997. doi: 10.1158/0008-5472.CAN-07-2017.

32. Baril P, Gangeswaran R, Mahon PC et al. Periostin promotes invasiveness and resistance of pancreatic cancer cells to hypoxia-induced cell death: role of the beta 4 integrin and the PI $3 k$ pathway. Oncogene. 2007;26:2082-2094. doi: 10.1038/sj.onc.1210009.

33. Adjei AA, Hidalgo M. Intracellular signal transduction pathway proteins as targets for cancer therapy. J Clin Oncol. 2005;23:5386-5403. doi: 10.1200/JCO.2005.23.648.

34. Faivre S, Djelloul S, Raymond E. New paradigms in anticancer therapy: targeting multiple signaling pathways with kinase inhibitors. Semin Oncol. 2006;33:407-420. doi: 10.1053/j. seminoncol.2006.04.005.

35. Engelman JA. Targeting PI3K signalling in cancer: opportunities, challenges and limitations. Nat Rev Cancer. 2009;9:550-562. doi: $10.1038 / \mathrm{nrc} 2664$.

36. Jechlinger M, Sommer A, Moriggl R et al. Autocrine PDGFR signaling promotes mammary cancer metastasis. J Clin Invest. 2006;116:1561-1570. doi: 10.1172/JCI24652.

37. Yan W, Shao R. Transduction of a mesenchyme-specific gene periostin into $293 \mathrm{~T}$ cells induces cell invasive activity through epithelial-mesenchymal transformation.J Biol Chem. 2006;281:19700-19708. doi: 10.1074/jbc.M601856200.

38. Kim CJ, Sakamoto K, Tambe Y, Inoue H. Opposite regulation of epithelial-to-mesenchymal transition and cell invasiveness by periostin between prostate and bladder cancer cells. Int J Oncol. 2011;38:1759-1766. doi: 10.3892/ijo.2011.997.

39. Wang W, Sun QK, He YF et al. Overexpression of periostin is significantly correlated to the tumor angiogenesis and poor prognosis in patients with esophageal squamous cell carcinoma. Int J Clin Exp Pathol. 2014;7:593-601. PMID: 24551279.

40. Nguyen TH. Mechanisms of metastasis. Clin Dermatol. 2004;22:209-216. doi: 10.1016/j.clindermatol.2003.12.007.

41. Ribatti D, Vacca A, Dammacco F. New non-angiogenesis dependent pathways for tumour growth. Eur J Cancer. 2003;39:1835-1841. doi: 10.1016/S0959-8049(03)00267-3.

42. Eliceiri BP, Cheresh DA. The role of alpha v integrins during angiogenesis: insights into potential mechanisms of action and clinical development. J Clin Invest. 1999;103:1227-1230. doi: $10.1172 /$ JCI6869.

43. Erber R, Thurnher A, Katsen AD et al. Combined inhibition of VEGF and PDGF signaling enforces tumor vessel regression by interfering with pericyte-mediated endothelial cell survival mechanisms. Faseb J. 2004;18:338-340. doi: 10.1096/ fi.03-0271fje.

44. Shao R, Bao S, Bai X et al. Acquired expression of periostin by human breast cancers promotes tumor angiogenesis through up-regulation of vascular endothelial growth factor receptor 2 expression. Mol Cell Biol. 2004;24:3992-4003. doi: $10.1128 /$ MCB.24.9.3992-4003.2004.

45. Song G, Ouyang G, Bao S . The activation of Akt/PKB signaling pathway and cell survival. J Cell Mol Med. 2005;9:59-71. doi: 10.1111/j.1582-4934.2005.tb00337.

46. Cheng GZ, Park S, Shu S et al. Advances of AKT pathway in human oncogenesis and as a target for anti-cancer drug discovery. Curr Cancer Drug Targets. 2008;8:2-6. doi: $\underline{10.2174 / 156800908783497159}$. 
47. Gabarra-Niecko V, Schaller MD, Dunty JM. FAK regulates biological processes important for the pathogenesis of cancer. Cancer Metastasis Rev. 2003;22:359-374. PMID: 12884911.

48. Puglisi F, Puppin C, Pegolo E et al. Expression of periostin in human breast cancer. J Clin Pathol. 2008;61:494-498. doi: 10.1136/jcp.2007.052506.

49. Takanami I, Abiko T, Koizumi S. Expression of periostin in patients with non-small cell lung cancer: correlation with angiogenesis and lymphangiogenesis. Int J Biol Markers. 2008;23:182-186. PMID: 18949745.

50. Takahashi M, Yoshimoto T, Kubo H. Molecular mechanisms of lymphangiogenesis. Int J Hematol. 2004;80:29-34. PMID: 15293565.

51. Saharinen P, Tammela T, Karkkainen MJ, Alitalo K. Lymphatic vasculature: development, molecular regulation and role in tumor metastasis and inflammation. Trends Immunol. 2004;25:387-395. doi: 10.1016/j.it.2004.05.003.

52. Kudo Y, Iizuka S, Yoshida $M$ et al. Periostin directly and indirectly promotes tumor lymphangiogenesis of head and neck cancer. PLoS One. 2012;7:e44488. doi: 10.1371/journal. pone. 0044488

53. Ji X, Chen D, Xu C, Harris SE, Mundy GR, Yoneda T. Patterns of gene expression associated with BMP-2-induced osteoblast and adipocyte differentiation of mesenchymal progenitor cell 3T3-F442A.J Bone Miner Metab. 2000;18:132-139. PMID: 10783846.

54. Oshima A, Tanabe H, Yan T, Lowe GN, Glackin CA, Kudo A A novel mechanism for the regulation of osteoblast differentiation: transcription of periostin, a member of the fasciclin I family, is regulated by the bHLH transcription factor, twist. J Cell Biochem. 2002;86:792-804. PMID: 12210745.

55. Haertel-Wiesmann M, Liang Y, Fantl WJ, Williams LT. Regulation of cyclooxygenase- 2 and periostin by Wnt- 3 in mouse mammary epithelial cells.J Biol Chem. 2000;275:32046-32051. doi: $10.1074 /$ jbc.M000074200.

56. Zhang Y, Zhang G, Li J, Tao Q, Tang W. The expression analysis of periostin in human breast cancer. J Surg Res. 2010;160:102-106. doi: $10.1016 /$ j.jss.2008.12.042.

57. $\mathrm{Xu} \mathrm{D}, \mathrm{Xu} \mathrm{H}$, Ren Y et al. Cancer stem cell-related gene periostin: a novel prognostic marker for breast cancer. PLoS One. 2012;7:e46670. doi: 10.1371/journal.pone.0046670.

58. Contie S, Voorzanger-Rousselot N, Litvin J, Clezardin P, Garnero P. Increased expression and serum levels of the stromal cell-secreted protein periostin in breast cancer bone metastases. Int J Cancer. 2011;128:352-360. doi: 10.1002/ ijc. 25591 .

59. Soltermann A, Tischler V, Arbogast $\mathrm{S}$ et al. Prognostic significance of epithelial-mesenchymal and mesenchymal-epithelial transition protein expression in non-small cell lung cancer. Clin Cancer Res. 2008;14:7430-7437. doi: 10.1158/1078-0432. CCR-08-0935.

60. Morra L, Rechsteiner M, Casagrande S et al. Characterization of periostin isoform pattern in non-small cell lung cancer. Lung Cancer. 2012;76:183-190. doi: 10.1016/j.lungcan.2011.10.013.

61. Hong L, Sun H, Lv X, Yang D, Zhang J, Shi Y. Expression of periostin in the serum of NSCLC and its function on proliferation and migration of human lung adenocarcinoma cell line (A549) in vitro. Mol Biol Rep. 2010;37:2285-2293. doi: 10.1007/s11033-009-9721-1.

62. Hong LZ, Wei XW, Chen JF, Shi Y. Overexpression of periostin predicts poor prognosis in non-small cell lung cancer. Oncol Lett. 2013;6:1595-1603. doi: $\underline{10.3892 /}$ ol.2013.1590.
63. Xiao ZM, Wang XY, Wang AM. Periostin induces chemoresistance in colon cancer cells through activation of the PI3K/ /Akt/survivin pathway. Biotechnol Appl Biochem. 2015;62: 401-406. doi: $10.1002 / \mathrm{bab} .1193$.

64. Kikuchi Y, Kunita A, Iwata $\mathrm{C}$ et al. The niche component periostin is produced by cancer-associated fibroblasts, supporting growth of gastric cancer through ERK activation. Am J Path. 2014;184:859-870. doi: 10.1016/j.ajpath.2013.11.01.

65. Lv H, Liu R, Fu J et al. Epithelial cell-derived periostin functions as a tumor suppressor in gastric cancer through stabilizing $\mathrm{p} 53$ and $\mathrm{E}$-cadherin proteins via the $\mathrm{Rb} / \mathrm{E} 2 \mathrm{~F} 1 / \mathrm{p} 14 \mathrm{ARF} /$ /Mdm2 signaling pathway. Cell Cycle. 2014;13:2962-2974. doi: 10.4161/15384101.2014.947203.

66. Li B, Wang L, Chi B. Upregulation of periostin prevents P53-mediated apoptosis in SGC-7901 gastric cancer cells. Mol Biol Rep. 2013;40:1677-1683. doi: 10.1007/s11033-012-2218-3.

67. Li JS, Sun GW, Wei XY, Tang WH. Expression of periostin and its clinicopathological relevance in gastric cancer. World $\mathrm{J} \mathrm{Ga}$ stroenterol. 2007;13:5261-5266. doi: 10.3748/wjg.v13.i39.5261.

68. Liu Y, Liu BA. Enhanced proliferation, invasion, and epithelial-mesenchymal transition of nicotine-promoted gastric cancer by periostin. World J Gastroenterol. 2011;17:2674-2680. doi: 10.3748/wjg.v17.i21.2674.

69. Ben QW, Jin XL, Liu J, Cai X, Yuan F, Yuan YZ. Periostin, a matrix specific protein, is associated with proliferation and invasion of pancreatic cancer. Oncol Rep. 2011;25:709-716. doi: 10.3892/or.2011.1140.

70. Tischler V, Fritzsche FR, Wild PJ et al. Periostin is up-regulated in high grade and high stage prostate cancer. BMC Cancer. 2010;10:273. doi: 10.1186/1471-2407-10-273.

71. Nuzzo PV, Rubagotti A, Zinoli L et al. Prognostic value of stromal and epithelial periostin expression in human prostate cancer: correlation with clinical pathological features and the risk of biochemical relapse or death. BMC Cancer. 2012;12:625. doi: 10.1186/1471-2407-12-625.

72. Tsunoda T, Furusato B, Takashima Y et al. The increased expression of periostin during early stages of prostate cancer and advanced stages of cancer stroma. Prostate. 2009;69:1398-1403. doi: 10.1002/pros.20988.

73. Chen J, Xi J, Tian Y, Bova GS, Zhang H. Identification, prioritization, and evaluation of glycoproteins for aggressive prostate cancer using quantitative glycoproteomics and antibody-based assays on tissue specimens. Proteomics. 2013;13:2268-2277. doi: 10.1002/pmic.201200541.

74. Sun C, Zhao X, Xu K. Periostin: a promising target of therapeutical intervention for prostate cancer. $J$ Transl Med. 2011;9:99. doi: 10.1186/1479-5876-9-99.

75. Argellati F, Nuzzo PV, Ricci F, Mangerini R, Rubagotti A, Boccardo F. Dihydrotestosterone and bicalutamide do not affect periostin expression in androgen-dependent $\mathrm{LNCaP}$ prostate cancer cell lines. Anticancer Res. 2013;33:815-820. PMID: 23482749.

76. Zhu M, Fejzo MS, Anderson L et al. Periostin promotes ovarian cancer angiogenesis and metastasis. Gynecol Oncol. 2010;119:337-344. doi: 10.1016/j.ygyno.2010.07.008.

77. Zhu M, Saxton RE, Ramos L et al. Neutralizing monoclonal antibody to periostin inhibits ovarian tumor growth and metastasis. Mol Cancer Ther. 2011;10:1500-1508. doi: 10.1158/1535-7163.MCT-11-0046.

78. Choi KU, Yun JS, Lee IH et al. Lysophosphatidic acid-induced expression of periostin in stromal cells: Prognoistic relevance of periostin expression in epithelial ovarian cancer. Int J Cancer. 2011;128:332-342. doi: 10.1002/ijc.25341.

79. Karlan BY, Dering J, Walsh C et al. POSTN/TGFBI-associated stromal signature predicts poor prognosis in serous 
epithelial ovarian cancer. Gynecol Oncol. 2014;132:334-342. doi: 10.1016/j.ygyno.2013.12.021.

80. Zhou W, Ke SQ, Huang $\mathrm{Z}$ et al. Periostin secreted by glioblastoma stem cells recruits M2 tumour-associated macrophages and promotes malignant growth. Nat Cell Biol. 2015;17:170-182. doi: 10.1038/ncb3090.
81. Mikheev AM, Mikheeva SA, Trister AD et al. Periostin is a novel therapeutic target that predicts and regulates glioma malignancy. Neuro Oncol. 2015;17:372-382. doi: 10.1093/neuonc/nou161.

82. Tian B, Zhang Y, Zhang J. Periostin is a new potential prognostic biomarker for glioma. Tumour Biol. 2014;35:5877-5883. doi: 10.1007/s13277-014-1778-3.

Submitted: 8 November, 2014 Accepted after reviews: 2 July, 2015 Available as AoP: 7 July, 2015 